\title{
Is Physical Activity, Functional Ability, and Depression Related to The Elderly Quality of Life in East Jakarta
}

\author{
Ratu Karel Lina ${ }^{1}$, Dwi Agustina ${ }^{2 *}$, Erna Sariana ${ }^{3}$, Azis Ritonga ${ }^{4}$ \\ 1,2,3,4 Health Polytechnic of Jakarta 3, Ministry of Health \\ Jln. Arteri JORR Jatiwarna, Pondok Melati Kota Bekasi Indonesia \\ ${ }^{*}$ Corresponding authors email: dwiagustinarosadi [AT] gmail.com
}

\begin{abstract}
Introduction: The global population is aging, and the number of elderly people continues to increase worldwide. The increase in the elderly population is followed by an increase in problems due to degenerative processes that have an impact on the quality of life of the elderly. Several factors that affect the quality of life of the elderly include physical activity, functional abilities, and depression.
\end{abstract}

Methodology: The study design was cross-sectional. Based on the quota sampling in East Jakarta, 180 elderly were selected as the sample. WHOQOL-BREF was used to measured quality of life of independent variables. GPAQ, IADL-Barthel Index, GDS were used to measure dependent variables of physical activity, functional ability and depression, respectively. The Data collection method was an interview using a questionnaire. Data analysis includes univariate and bivariate analysis using Chi-Square test and multivariate analysis using Logistic Statistics test using Enter method.

Results: Most of the elderly have a good quality of life (77.2\%). There was a significant corellation between physical activity, functional ability, depression and the quality of life of the elderly. The most important factor was physical activity and the $\mathrm{P}$ values and OR were 0.014 and OR 3.409, respectively after being controlled by the variables of functional ability and depression.

Conclusion: The finding indicated physical activity was the key factor of quality of life. In order to support elderly to exercise regularly and safely, cooperation between local governments, communities, and families is needed to develop interesting exercise/leisure sport programs and provide support facilities for the elderly.

Keywords - quality of life, physical activity, functional ability, depression, elderly

\section{INTRODUCTION}

Humans from birth go through several phases of life, from infancy, childhood, adolescence, adulthood to senescence. Aging is a natural process that occurs in all human beings. [1]. Biologically, the aging process is a result of the accumulation of molecular and cellular damage over time, which gradually leads to a decline in physical and mental capacities [2]. The aging process is usually accompanied by a decline in physical, psychological and social conditions, due to the mutual influence of physical, psychological and social conditions due to age [3]. Decreased capacity and condition in the elderly can be seen from changes in physical appearance, changes in the nervous system and organs in the body, changes in the function of the five senses and decreased motor skills [3,4].

Physical changes and health conditions decline, which are also exacerbated by transitions in life such as retirement, feelings of deep loss (bereavement), especially spouses and relatives or close friends, feelings of loneliness to depression, and forgetfulness (dementia), affect elderly physiologically and psychologically. In addition, with the increase of age, the elderly tend to suffer from multiple diseases at the same time [2,3]. Physical changes gradually lead to deterioration of health conditions such as back and neck pain, hypertension or increased blood pressure, arthritis, stroke, chronic pulmonary obstruction, diabetes. In terms of activities of daily living (ADL), the elderly also begin to experience an inability to take care of themselves, such as bathing, defecating, dressing, combing their hair, eating so that they need help from others $[3,5]$.

Currently, the world's elderly population is increasing rapidly. In 2019, the elderly population over 65 years old reached 703 million, and it will increase to 1.5 billion by 2050 [4]. With the rapid increase in the elderly population, the problems arising from degenerative processes will also increase. The elderly need special attention to maintain their healthy, independence, social, and economic productivity under human dignity. Healthy aging is "the process of developing and maintaining the functional abilities that enables well-being in older age" [5]. Healthy aging is expected to have an impact on the quality of life (QOL) of the elderly [6]. 
The term quality of life is a broad, dynamic, multidimensional concept, both subjective and objective, covering three domains, namely physical health, psychological, and social relationships. $[9,10]$. The quality of life of the elderly is affected by many factors, one of which is physical activity. For a long time, Physical activity has been considered an important part of health and QOL. Regular physical activity can improve physical and mental health status in general, which result in the optimal QOL for a person [9]. A meta-analysis reviewed 42 studies and found that most studies show a positive correlation between physical activity and quality of life in the elderly [10]. Other studies using structural equation modeling (SEM) analysis have shown that there was an indirect relationship between physical activity and QOL. In McAuley's study, physical activity affected self-efficacy and QOL through physical and mental health, which in turn affected global QOL [11].

QOL is also affected by depression and functional ability. Raggi et al. found that sadness and depression contribute to lower QOL in older people [6]. Other studies conducted by Trajkov et al. [12], Bottan et al. [13] dan Soósová [14] showed that depression is associated with lower QOL in the elderly. Another factor that is no less important to the quality of life is functional ability. The elderly who are still able to carry out ADL independently have a positive relationship with QOL [14]. The study conducted by Rosińczuk \& Kołtuniuk on Parkinson's patient found that patients with higher functional levels had a better QOL [15]

The purpose of this study was to determine the relationship between physical activity, functional ability, and depression with the QOL of the elderly who live in East Jakarta.

\section{METHODOLOGY}

The current study type was classified as a descriptive-analytic with a cross-sectional design. According to the Lemeshow formula estimation sample of two proportions [16], the 180 elderly over 60 years old and with good memory in the East Jakarta were selected using a quota sampling. The research was conducted in April-October 2019 using an interview to collect data. The research sample was asked for consent before participating in the study.

The research variables included the dependent variable, namely the quality of life, and independent variables included functional ability, physical activity, and depression. The Indonesian translation of WHOQOL-BREF [17] was used to measure QOL. WHOQOL-BREF contains 26 questions. The first two questions are about the individual's overall perception of the quality of life and health, and the other 24 questions are about the quality of life domain. Each question was scored 1-5, unless questions 1 and 2 were not counted, the total score categorized into poor if $<60$, and good if $\geq 60$. Depression was measured by the Geriatric Depression Scale (GDS) instrument of the Indonesian Ministry of Health [18], which was adapted from the GDS instrument developed by Yasavage \& Sheikh [19]. The GDS instrument contains 15 questions of 2 "yes" or "no" answer options. The score for each question is $0-1$, and the results were summed. If the total score is $\geq 5$, then it was classified as depression, if $<5$ was normal. Physical activity was measured by the WHO global physical activity questionnaire [20] which was translated into Indonesian. The questionnaire consisted of 16 questions divided into three domains, namely activities at work, traveling to and from places, and recreational activities, including sedentary behavior. Physical activity was expressed in terms of MET-minutes per week or time spent on physical activity. MET was obtained by multiplying the total duration of moderate-intensity physical activity by 4 and vigorous intensity by 8 , for one week. The results were then summed and classified as active if total MET $\geq 600$, inactive if $<600$ [21]. Functional ability was measured using the Activities of Daily Living (ADL) instrument of the Ministry of Health of the Republic of Indonesia [18], which was adapted from the Barthel Index [22]. Each question was scored then grouped into self-reliant if total score $\geq 20$ and dependent if total score $<20$.

Data processing used SPSS version 26. Data analysis included univariate and bivariate analysis with the Chi-Square test. The multivariate analysis of the binomial logistic regression enter method was carried to obtain the best model in seeing the correlation between physical activity, depression, and functional ability with the QOL of the elderly. The first stage in this test was variable selection using the bivariate test, and all variables with a p-value $<0.25$ would be entered as candidates which were included in the test in multivariate analysis simultaneously. In the next multivariate analysis, the best model was chosen by considering several assessment conditions, namely the significant value of the log-likelihood ratio $(p<0.05)$, the percentage of correct classification relatively large, the significant value of $p=$ Wald $(p<0.05)$, the odds ratio (OR) value and the stability of the OR value [23].

\section{RESULTS AND DISCUSSION}

\subsection{Results}

The characteristics of the research sample indicated that most of the samples were women, accounting for $71.7 \%$, and only $28.3 \%$ of men. Most of the respondents' education level was low ( $\leq$ elementary school) which was $71.1 \%$, the remaining $23.9 \%$ has moderate education (junior high/high school). The average age of the samples participating in this 
study was 69 years old, ranging from 60 to 83 years old, with the highest percentage of $60-74$ years old (76.1\%), and the rest $>75$ years old (23.9\%). For more details, see Table1 below:

Table 1: Frequency distribution of elderly characteristics

\begin{tabular}{lcc}
\hline \multicolumn{1}{c}{ Variable } & Frequency (n) & Percentage $(\%)$ \\
\hline Gender & & \\
Male & 51 & 28,3 \\
Female & 129 & 71,7 \\
Education & & \\
Low & 128 & 71,1 \\
Medium & 52 & 28,9 \\
Age (years) & & \\
$60-74$ & 137 & 76,1 \\
$>75$ & 43 & 23,9 \\
\hline
\end{tabular}

Table 2 below, lists the respondents according to the main variables studied, such as the quality of life of the elderly, physical activity, depression, and functional ability.

Table 2: Distribution of frequency of quality of life, physical activity, depression and functional ability in the elderly

\begin{tabular}{lcc}
\hline \multicolumn{1}{c}{ Variable } & Frequency (n) & Percentage (\%) \\
\hline Quality of life & & \\
Poor & 41 & 22,8 \\
Good & 139 & 77,2 \\
Physical activity & & \\
Inactive & 41 & 22,8 \\
Active & 139 & 77,2 \\
Functional ability & & \\
Dependent & 56 & 31,1 \\
Self-reliant & 124 & 68,9 \\
Depression & & \\
Depression & 57 & 31,7 \\
Normal & 123 & 68,3 \\
\hline
\end{tabular}

It can be seen from Table 2 that most elderly have a good quality of life, as many as 139 (77.2\%), and only $22.8 \%$ of the poor. Correspondingly, in the physical activity, most of the elderly were active, accounting for $77.2 \%$, and the remaining $22.8 \%$ were inactive. Slightly different from the previous two variables, the proportion of depression in the elderly was slightly higher, at $31.7 \%$, while the remaining $68.3 \%$ were normal. This figure is not much different from the functional ability of the elderly, which only shows that $31.1 \%$ of elderly were dependent, while most eldery were self-reliant, that was up to $68.9 \%$.

The results of the bivariate analysis showed that all dependent variables, namely physical activity, depression, and functional ability, had a significant relationship with the dependent variable of QOL. The elderly who were physically active tend to have a good quality of life. This could be seen from the greater percentage of an active elderly with a good quality of life compared to those who were inactive, namely $85.6 \%$ and $48.8 \%$, respectively. On the other hand, the inactive elderly with poor quality of life $(51.2 \%)$ were also higher than those who were physically active (14.4\%). The statistical analysis resulted in a $\mathrm{p}$-value of $0.0001(\mathrm{p}<\alpha=0.05)$ which indicated a significant relationship between physical activity and the quality of life. For more details, see Table 3. 
Table 3: Corelation between physical activity, functional ability \& depression and the quality of life of the elderly

\begin{tabular}{|c|c|c|c|c|c|c|c|}
\hline \multirow{3}{*}{ Dependent variable } & \multicolumn{4}{|c|}{ Quality of life } & \multicolumn{2}{|c|}{ Total } & \multirow{3}{*}{$p$ value } \\
\hline & \multicolumn{2}{|c|}{ Poor } & \multicolumn{2}{|c|}{ Good } & \multirow{2}{*}{$\mathrm{n}$} & \multirow{2}{*}{$\%$} & \\
\hline & $\mathrm{n}$ & $\%$ & $\mathrm{n}$ & $\%$ & & & \\
\hline \multicolumn{8}{|l|}{ Physical activity } \\
\hline Inactive & 21 & 51,2 & 20 & 48,8 & 41 & 100,0 & \multirow{2}{*}{0,0001} \\
\hline Active & 20 & 14,4 & 119 & 85,6 & 139 & 100,0 & \\
\hline \multicolumn{8}{|l|}{ Functional ability } \\
\hline Dependent & 25 & 43,9 & 32 & 56,1 & 57 & 100,0 & \multirow{2}{*}{0,0001} \\
\hline Self-reliant & 16 & 13,0 & 107 & 87,0 & 123 & 100,0 & \\
\hline \multicolumn{8}{|l|}{ Depression } \\
\hline Depression & 20 & 35,7 & 36 & 64,3 & 56 & 100,0 & \multirow[b]{2}{*}{0,010} \\
\hline Normal & 21 & 16,9 & 103 & 83,1 & 124 & 100,0 & \\
\hline
\end{tabular}

Depression also showed the same result, that was elderly who experienced depression with poor quality of life (35.7\%) were larger than normal elderly $(16,9)$. On the other hand, the normal elderly with a good quality of life $(83.2 \%)$ were also higher than those with depression (64.3\%). The statistical analysis result showed that the p-value of 0.0001 was $<\alpha(0,05)$. In conclusion, there was a significant relationship between depression and the quality of life of the elderly.

The relationship between the functional capacity of the elderly and the quality of life showed that dependent elderly with lower quality of life $(43.9 \%)$ were much larger than the self-reliant elderly (13\%). On the contrary, the self-reliant elderly with good quality of life $(87.0 \%)$ were also higher than those with dependents $(56.1 \%)$. Statistical analysis showed that the p-value was $0.010(\mathrm{p}<\alpha=0.05)$, it indicated that there was a significant relationship between the functional ability of the elderly and the quality of life.

In order to determine the variables that have the greatest contribution on the quality of life of the elderly, a multivariate analysis was performed using the binomial logistic regression enter method. The first step of the multivariate analysis was the variable selection, and the results were as Tabel 4 follow:

Table 4: Independent Variable Selection Results

\begin{tabular}{lccl}
\hline \multicolumn{1}{c}{ Variable } & Df & $p$ value & Info \\
\hline Physical activity & 1 & 0,000 & Candidate \\
Depression & 1 & 0,000 & Candidate \\
Functional ability & 1 & 0,007 & Candidate \\
\hline
\end{tabular}

The selection results in Table 4 showed that no variable had a p-value $>0.25$, so all these variables were candidates for multivariate analysis. Furthermore, a multivariate analysis was performed to obtain the best model of the relationship between physical activity, functional ability, and depression, and the quality of life of the elderly. The results of modeling using multivariate analysis were shown in Table 5 below:

Table 5: The Results of modeling the relationship between physical activity, depression, and functional capabilities with quality of life

\begin{tabular}{lccccccc}
\hline \multirow{2}{*}{ Variabel } & \multicolumn{2}{c}{ Modeling I } & \multicolumn{2}{c}{ Modeling II } & \multicolumn{4}{c}{ Modeling III } \\
\cline { 2 - 8 } & $\mathrm{P}$ & OR & P & OR & P & OR & CI.95\% \\
\hline Physical activity & 0,014 & 3,409 & 0,014 & 3,409 & 0,014 & 3,409 & $1,278-9,090$ \\
Depression & 0,107 & 2,218 & 0,106 & 1,930 & 0,107 & 2,218 & $0,842-5,843$ \\
Functional ability & 0,106 & 1,930 & 0,107 & 2,218 & 0,106 & 2,096 & $0.870-4,284$ \\
\hline
\end{tabular}

It can be seen from Table 5 that there was only one variable with a p-value of $<0.05$, namely physical activity. Hence, it can be concluded that physical activity variables have a significant relationship with the quality of life of the elderly. The results of the multivariate analysis also showed that the dominant factor that have the greatest impact on QOL was physical activity, with an OR value of 3.409, which means that active elderly have a chance of 3.409 times higher to a better quality of life compared to those inactive elderly. At the same time, the variables of depression and functional ability were considered confounding variables as the OR changes $>10 \%$, and the p-value $>0,05$, in the multivariate analysis. 


\subsection{Discussion}

Quality of life is a broad concept, often referred to as subjective well-being, happiness, and life satisfaction [24]. Quality of life is a dynamic concept that can change over time based on experience, present circumstances, and expectations for the future [7]. The quality of life typically encompasses all aspects of life, including physical, emotional, social, environmental, and material. Moreover, quality of life describes the environment of an individual's life, the opportunity to obtain life services, and other things related to happiness, love, life satisfaction, and accomplishment of an individual's needs $[27,28]$. In the health sector, the term quality of life is derived from the term " well-being " within the definition of "health" by the WHO [27]. According to WHO, the quality of life is "individuals' perception of their position in life in the context of the culture and value systems in which they live and concerning their goals, expectations, standards, and concerns." It is a wide range of concepts that combine personal physical health, mental state, independence, social relations, personal beliefs, and their relationship with the salient features of the environment in a complex way [28].

In this study, the majority of the elderly, namely $77.2 \%$, had a good quality of life. Many factors affect the quality of life of the elderly, one of which is physical activity. The results showed that most of the elderly were active as many as 139 people (77.2\%), while the inactive elderly were only 41 people (22.8\%). Physical activity was the dominant variable affecting the quality of life, with an OR of 3.409. This fact suggested that the elderly with active physical activity were 3.4 times more likely to have a good quality of life when compared to the elderly who were inactive.

Physical activity is "any bodily movement produced by the contraction of skeletal muscles that result in a substantial increase over resting energy expenditure" [29]. While exercise is "physical activity that is planned, structured, and continuous with body movements that are repetitive and aimed at improving physical fitness" [29]. According to the World Health Organization recommendations, the elderly over the age of 65 should perform at least 150 minutes of moderateintensity aerobic physical activity per week or perform equivalence physical activity consisted both moderate-intensity aerobic physical activity and vigorous-intensity aerobic physical activity [21]. The duration of aerobic activity should last at least 10 minutes. Do muscle exercises at least twice a week. According to the recommendations of the American College of Sports Medicine (ACSM), the elderly who have no physical limitations regularly perform physical exercises, including aerobic exercise, muscle exercise, flexibility, and balance training [30]. WHO and ACSM also recommend the elderly to stay physically active under their conditions, even though they have a problem due to their deteriorating health [23,32].

The elderly should adjust their physical activity and exercise based on conditions. Most people who have reached the age of 65 years and over are advised to reduce vigorous intensity-physical activity, but not simply stop. There are many choices of types of exercises or physical activities for the elderly that can be tailored to their needs. For moderate-intensity activity, for example, walking short distances, cleaning the house, cycling casually, climbing stairs, gardening. Meanwhile, vigorous-intensity activities include swimming, tai chi, yoga, jogging, brisk walking, carrying children, to badminton $[32,33]$.

Physical activity has a positive impact on physical health, psychologic[32]al, and quality of life. Physical activity can foster a healthier maximize positive emotion, satisfaction, happiness, and adaptability to psychosocial changes [33]. Various other studies have also shown a positive relationship between physical activity and quality of life [32-33,34-[36]. Regular physical activity can enhance muscle strength, balance, and cognitive function, which is an essential component for the elderly to carry out daily activities, which affect the quality of life [37].

In this study, the ability of the elderly to perform daily activities was an indicator of functional ability. The result of functional ability measurement showed that the majority of the elderly were self-reliant, as many as 124 people (68.9\%), only 57 people (31.7\%) were dependent. The bivariate analysis found a significant relationship between functional abilities and quality of life in the elderly. On the contrary, in the multivariate analysis, there was no significant relationship between functional ability and quality of life, so it was considered a confounding variable.

Functional ability is "people's ability to carry out daily activities independently and autonomously while staying in contact with their home environment" [38]. Functional ability demonstrates the physical fitness needed to perform daily activities independently without feeling exhausted. The aging process tends to reduce physical fitness that includes strength, endurance, agility, and flexibility, resulting in the elderly having difficulty carrying out their normal functions and ADL. The functional ability of the elderly in carrying out ADL decreases with age [39].

Various studies have shown that functional ability has an impact on the quality of life of the elderly. The study conducted by Talarska et al. found that functional ability has a significant relationship with all domains of quality of life, including physical health, psychological, social relationships, and the environment. Talarska et al. also found that the functional ability of the elderly above 75 years old had decreased, therefore require more attention [40]. The study conducted in Indonesia by Clifford et al. found functional ability has a significant relationship with quality of life [32]. The study conducted at nursing homes in Southern Taiwan has also shown that functional ability had a positive relationship with quality of life [41]. 
The mental health of the elderly is another aspect that also influences the quality of life of the elderly. In this study, only 57 people $(31.7 \%)$ experienced depression, while the remaining $123(68.3 \%)$ normal. In the bivariate analysis, depression demonstrated a significant relationship to quality of life. However, after the multivariate test was carried out, depression did not have a significant relationship as seen by the $p$-value of $0.107,(\alpha=0.05)$, so it was considered as a confounding variable.

Depression is a mental disorder that is usually characterized by depressed mood, loss of interest in activities or pleasure, feelings of guilt and hopelessness, or low self-worth, disturbed sleep or appetite, fatigue or low energy, restlessness, poor concentration, and suicidal ideation. The effect of depression on each person is different so that the symptoms that appear also vary $[42,43]$. Depression can occur in the elderly, but many are not diagnosed, so there is no special care. The main undetected cause of depression in the elderly is probably due to depression caused by other diseases. Moreover, the elderly who experience depression usually have less obvious symptoms. The desire or feeling of suicidal thoughts is a serious symptom that requires special attention, especially in men, as men tend to have a higher risk of suicide [42].

Depression has a negative association with quality of life, and the elderly with depression seem to have a low quality of life. Research conducted by Trajkov et al. has shown that the higher the quality of life, the lower the depression[12]. The study in Southern Brazil in the semi-rural Italian town of Veranópolis found that elderly who were dissatisfied with their quality of life demonstrated symptoms of depression [44]. Other studies conducted by Sertel et al., Bottan et al., and Soósová showed that depression is associated with reduced quality of life in the elderly $[13,14,45]$.

An important finding in this study is that physical activity is the dominant variable that most plays a role in quality of life. This finding is in line with the results of other studies that show physical activity is a key factor in the quality of life of the elderly. Seniors who exercise more often have lower rates of depression and higher quality of life [12,46,47]. In addition, the active elderly have better functional abilities that affect a better quality of life [35,38,48-49]. Physical activity plays an important role in improving the physical fitness of the elderly, which is the main component of ADL. Participating in regular physical activities will provide an opportunity to meet with friends to develop relationships that affect emotional and psychological aspects. All parties should cooperate so that the elderly can safely perform regular physical activities. Health offices and health centers should work with local communities and elderly families to develop fun exercise programs for the elderly. At the same time, local governments should provide auxiliary facilities such as parks, sports centers, bicycle lanes, and pedestrians.

The limitation or shortcoming of current study was that the dependent variables were only physical activity, functional ability, and depression, so other variables related to the quality of life of the elderly may have been evaluated. Moreover, this study design was cross-sectional. Concerning the study design, the results of the current study could not be generalized to various research locations and times as the independent and dependent variables were measured at the same time.

\section{CONCLUSSION}

The results of the analysis showed that most elderly people had a good quality of life, were active, self-reliant, normal, or not depressed. Physical activity is the dominant predictor that plays an important role in the quality of life with OR 3.409, which means that older people with active physical activity have a greater chance of having a successful quality of life 3.409 times higher than those that are not active. Physical activity was the dominant predictor that plays an important role in the quality of life. The OR of 3.409, suggested that older people with active physical activity have a greater chance of having a good quality of life 3.409 times higher than those that were not active. For this purpose, the collaboration between all parties is required so that the elderly can conduct regular physical activities safely, by creating an enjoyable exercise program for the elderly and by providing support facilities such as a park, sports center, special walking, and cycling path.

The quality of life of the elderly has become an important part of health promotion in line with the aging population trend. Similar research can be developed by incorporating several variables related to the quality of life of the elderly, such as demographic characteristics, social ties, factors related to health services, including the role of health workers, environmental factors and sources of communication, information, education and awareness for the elderly.

\section{REFERENCES}

[1] K. S. and M. S. Shilpa Amarya and Additional, "Ageing process and physiological changes," Intech, p. 13, 2012, doi: 10.5772/intechopen.76249.

[2] Word Health Organization, "Ageing and health," Word Health Organization, 2018. http://www.who.int/newsroom/fact-sheets/detail/ageing-and-health (accessed Nov. 11, 2018).

[3] A. Santika, "Lanjut usia dalam perspektif hukum dan HAM," Bul. Jendela Data dan Inf. Kesehat., vol. 1, pp. 2932, 2013.

[4] United Nation, World Population Ageing 2019: Highlights (ST/ESA/SER.A/430). Official. 2019. 
[5] World Health Organization, "World Report on Ageing and Health," Geneva, 2015.

[6] A. Raggi et al., "Determinants of quality of life in ageing populations: Results from a cross-sectional study in Finland, Poland and Spain," PLoS One, vol. 11, no. 7, pp. 1-17, 2016, doi: 10.1371/journal.pone.0159293.

[7] X. J. Lin, I. M. Lin, and S. Y. Fan, "Methodological issues in measuring health-related quality of life," Tzu Chi Medical Journal, vol. 25, no. 1. No longer published by Elsevier, pp. 8-12, Mar. 01, 2013, doi: 10.1016/j.tcmj.2012.09.002.

[8] G. Netuveli and D. Blane, "Quality of life in older ages," British Medical Bulletin, vol. 85, no. 1. Oxford Academic, pp. 113-126, Mar. 01, 2008, doi: 10.1093/bmb/ldn003.

[9] T. T. Su, M. Azzani, A. P. Adewale, N. Thangiah, R. Zainol, and H. Majid, "Physical activity and health-related quality of life among low-income adults in Metropolitan Kuala Lumpur,” J. Epidemiol., vol. 29, no. 2, pp. 43-49, 2019, doi: 10.2188/jea.JE20170183.

[10] G. C. Vagetti, V. C. Barbosa Filho, N. B. Moreira, V. de Oliveira, O. Mazzardo, and W. de Campos, “Association between physical activity and quality of life in the elderly: A systematic review, 2000-2012," Rev. Bras. Psiquiatr., vol. 36, no. 1, pp. 76-88, 2014, doi: 10.1590/1516-4446-2012-0895.

[11] E. McAuley, J. F. Konopack, R. W. Motl, K. S. Morris, S. E. Doerksen, and K. R. Rosengren, "Physical activity and quality of life in older adults: Influence of health status and self-efficacy," Ann. Behav. Med., vol. 31, no. 1, pp. 99-103, Feb. 2006, doi: 10.1207/s15324796abm3101_14.

[12] M. Trajkov, F. Eminovic, S. Radovanovic, M. Dopsaj, D. Pavlovic, and D. Kljajic, "Quality of life and depression in elderly persons engaged in physical activities," Vojnosanit. Pregl. Med. Pharm. J. Serbia, vol. 75, no. 2, pp. 177184, 2018, doi: 10.2298/vsp160329336t.

[13] G. Bottan, E. P. De Morais, J. F. Schneider, C. Trentini, and E. Heldt, "Determinants of quality of life in elderly patients of a psychosocial care center in Brazil," Issues Ment. Health Nurs., vol. 35, no. 3, pp. 181-188, 2014, doi: 10.3109/01612840.2013.849782.

[14] M. S. Soósová, "Determinants of quality of life in the elderly," Cent. Eur. J. Nurs. Midwifery, vol. 7, no. 3, pp. 484493, 2016, doi: 10.15452/CEJNM.2016.07.0019.

[15] J. Rosińczuk and A. Kołtuniuk, “The influence of depression, level of functioning in everyday life, and illness acceptance on quality of life in patients with parkinson's disease: A preliminary study," Neuropsychiatr. Dis. Treat., vol. 13, pp. 881-887, Mar. 2017, doi: 10.2147/NDT.S132757.

[16] S. K. Lwanga and S. Lemeshow, Sample Size Determination in Health Studies: A Practical Manual. Geneva: World Health Organization, 1991.

[17] World Health Organization, "WHOQOL-BREF Introduction, Administration, Scoring and Generic Version of the Assessment." World Health Organization, Geneva, 1996.

[18] Kementerian Kesehatan Republik Indonesia, "Instrumen Pengkajian Paripurna Pasien Geriatri (P3G).” Kementerian Kesehatan Republik Indonesia, Jakarta, 2017, [Online]. Available: http://kesga.kemkes.go.id/images/pedoman/INSTRUMEN P3G.pdf.

[19] J. A. Yesavage and J. I. Sheikh, "9/Geriatric Depression Scale (GDS): Recent Evidence and Development of a Shorter Version,” Clin. Gerontol., vol. 5, no. 1-2, pp. 165-173, Nov. 1986, doi: 10.1300/J018v05n01_09.

[20] World Health Organization, "Global Physical Activity Questionnaire (GPAQ) Analysis Guide," World Health Organization. Geneva, pp. 1-22, 2012, [Online]. Available:

http://scholar.google.com/scholar?hl=en\&btnG=Search\&q=intitle:Global+Physical+Activity+Questionnaire+(GPA Q)+Analysis+Guide\#1.

[21] World Health Organization, Global Recommendations on Physical Activity for Health. Geneva: World Health Organization, 2010.

[22] F. I. Mahoney and D. W. Barthel, "Functional evaluation: The Barthel index," Md. State Med. J., vol. 14, no. 4, pp. 61-5, Feb. 1965, [Online]. Available: http://www.ncbi.nlm.nih.gov/pubmed/14258950.

[23] S. P. Hastono, Analisa Data Bidang Kesehatan. Jakarta: Universitas Indonesia, 2016.

[24] B. G. Berger, "Physical activity and quality of life: Key considerations," in Handbook of Sport Psychology, 3rd ed., G. Tenenbaum and R. C. Eklund, Eds. John Wiley \& Sons, 2007.

[25] T. Boggatz, "Quality of life in old age - a concept analysis,” Int. J. Older People Nurs., vol. 11, no. 1, pp. 55-69, Mar. 2016, doi: 10.1111/opn.12089. 
[26] S. De, R. Nath Roy, K. Mitra, D. Kumar Das, and A. Dan, "Physical activities and quality of life among elderly population in urban slum of Bardhaman Municipality, West Bengal," IOSR J. Dent. Med. Sci. e-ISSN, vol. 17, pp. 67-73, 2018, doi: 10.9790/0853-1705126773.

[27] World Health Organization, "The Constitution of the World Health Organization.” World Health Organization, New York, 1946.

[28] The WHOQOL Group, “The World Health Organization quality of life assessment (WHOQOL): Position paper from the World Health Organization," Soc. Sci. Med., vol. 41, no. 10, pp. 1403-1409, Nov. 1995, doi: 10.1016/0277-9536(95)00112-K.

[29] C. E. Garber et al., "Quantity and quality of exercise for developing and maintaining cardiorespiratory, musculoskeletal, and neuromotor fitness in apparently healthy adults: Guidance for prescribing exercise," Med. Sci. Sports Exerc., vol. 43, no. 7, pp. 1334-1359, Jul. 2011, doi: 10.1249/MSS.0b013e318213fefb.

[30] C. Kisner, L. A. Colby, and J. Borstad, Therapeutic Exercise : Foundations and Techniques, Seventh ed. Philadelphia: F.A. Davis Company, 2018.

[31] Kementerian Kesehatan RI, “Aktivitas Fisik Untuk Lansia,” 2018. https://promkes.kemkes.go.id/?p=8816 (accessed Oct. 13, 2020).

[32] A. Clifford, T. B. Rahardjo, S. Bandelow, and E. Hogervorst, "A cross-sectional study of physical activity and health-related quality of life in an elderly Indonesian cohort," Br. J. Occup. Ther., vol. 77, no. 9, pp. 451-456, 2014, doi: 10.4276/030802214X14098207541036.

[33] M. Slimani, R. Ramirez-Campillo, A. Paravlic, L. D. Hayes, N. L. Bragazzi, and M. Sellami, "The effects of physical training on quality of life, aerobic capacity, and cardiac function in older patients with heart failure: A meta-analysis," Front. Physiol., vol. 9, 2018, doi: 10.3389/fphys.2018.01564.

[34] C. Matz-Costa, E. Besen, J. Boone James, and M. Pitt-Catsouphes, "Differential impact of multiple levels of productive activity engagement on psychological well-being in middle and later life," Gerontologist, vol. 54, no. 2, pp. 277-289, Apr. 2014, doi: 10.1093/geront/gns148.

[35] J. A. Liffiton, S. Horton, J. Baker, and P. L. Weir, "Successful aging: How does physical activity influence engagement with life?," European Review of Aging and Physical Activity, vol. 9, no. 2. BioMed Central, pp. 103108, Apr. 04, 2012, doi: 10.1007/s11556-012-0098-0.

[36] L. M. Ramocha, Q. A. Louw, and M. D. Tshabalala, "Quality of life and physical activity among older adults living in institutions compared to the community," South African J. Physiother., vol. 73, no. 1, 2017, doi: 10.4102/sajp.v73i1.342.

[37] U. Svantesson, J. Jones, K. Wolbert, and M. Alricsson, "Impact of physical activity on the self-perceived quality of life in non-frail older adults," J. Clin. Med. Res., vol. 7, no. 8, pp. 585-593, Jun. 2015, doi: 10.14740/jocmr2021w.

[38] A. Oliveira, P. Nossa, and A. Mota-Pinto, “Assessing functional capacity and factors determining functional decline in the elderly: A Cross-sectional study - Avaliação da capacidade funcional e fatores determinantes do declínio funcional em idosos: Um estudo transversal," Acta Med. Port., vol. 32, no. 10, pp. 654-660, Oct. 2019, doi: 10.20344/amp.11974.

[39] Z. Milanović, S. Pantelić, N. Trajković, G. Sporiš, R. Kostić, and N. James, “Age-related decrease in physical activity and functional fitness among elderly men and women," Clin. Interv. Aging, vol. 8, pp. 549-556, 2013, doi: 10.2147/CIA.S44112.

[40] D. Talarska, S. Tobis, M. Kotkowiak, M. Strugała, J. Stanisławska, and K. Wieczorowska-Tobis, "Determinants of quality of life and the need for support for the elderly with good physical and mental functioning," Med. Sci. Monit., vol. 24, pp. 1604-1613, 2018, doi: 10.12659/MSM.907032.

[41] S. Z. Tseng and R. H. Wang, "Quality of life and related factors among elderly nursing home residents in Southern Taiwan,” Public Health Nurs., vol. 18, no. 5, pp. 304-311, Sep. 2001, doi: 10.1046/j.1525-1446.2001.00304.x.

[42] D. Bhowmik, K. P. Sampath Kumar, S. Srivastava, S. Paswan, and A. S. Dutta, "Depression-symptoms, causes, medications and therapies," Pharma Innov. J., vol. 1, no. 3, pp. 41-55, 2012, [Online]. Available: https://www.thepharmajournal.com/archives/2012/vol1issue3/PartA/5.pdf.

[43] R. Arena et al., "Assessment of functional capacity in clinical and research settings: A scientific statement from the American Heart Association committee on exercise, rehabilitation, and prevention of the council on clinical cardiology and the council on cardiovascular nursing," Circulation, vol. 116, no. 3. Lippincott Williams \& Wilkins, 
pp. 329-343, Jul. 17, 2007, doi: 10.1161/CIRCULATIONAHA.106.184461.

[44] F. M. F. Xavier, M. P. T. Ferraz, N. Marc, N. U. Escosteguy, and E. H. Moriguchi, “Elderly people's definition of quality of life," Rev. Bras. Psiquiatr., vol. 25, no. 1, pp. 31-39, 2003, doi: 10.1590/S1516-44462003000100007.

[45] M. Sertel, S. A. Arslan, F. Kurtoğlu, and T. Ş. Yıldırım, "Physical activity, depression and quality of life in aging process," Biomed. Res., vol. 28, no. 9, pp. 4165-4170, 2017.

[46] H. Y. Yen and L. J. Lin, "Quality of life in older adults: Benefits from the productive engagement in physical activity," J. Exerc. Sci. Fit., vol. 16, no. 2, pp. 49-54, Aug. 2018, doi: 10.1016/j.jesf.2018.06.001.

[47] S. K. Dewi, "Level aktivitas fisik dan kualitas hidup warga lanjut usia," Media Kesehat. Masy. Indones., vol. 14, no. 3, p. 241, 2018, doi: 10.30597/mkmi.v14i3.4604.

[48] A. M. Imoto, M. S. Peccin, and V. F. M. Trevisani, "Quadriceps strengthening exercises are effective in improving pain, function and quality of life in patients with osteoarthritis of the knee," Acta Ortop. Bras., vol. 20, no. 3, pp. 174179, 2012, doi: 10.1590/S1413-78522012000300008.

[49] S. M. Phillips, T. R. Wójcicki, and E. McAuley, "Physical activity and quality of life in older adults: An 18-month panel analysis," Qual. Life Res., vol. 22, no. 7, pp. 1647-1654, 2013, doi: 10.1007/s11136-012-0319-z. 